\title{
Special issue of selected papers from the 5th European Section Meeting of the International Academy of Cardiovascular Sciences held in Smolenice, Slovakia, on 23-26 May 2018
}

\author{
Guest Editors \\ Jan Slezak \\ Centre of Experimental Medicine \\ Institute for Heart Research \\ Slovak Academy of Sciences \\ Bratislava, Slovak Republic \\ Tatiana Ravingerova \\ Centre of Excellence \\ Institute for Heart Research \\ Slovak Academy of Sciences \\ Bratislava, Slovak Republic \\ Dragan Djuric \\ Institute of Medical Physiology "Richard Burian" \\ Faculty of Medicine \\ University of Belgrade \\ Belgrade, Serbia
}

